\title{
A Sequential Approach for Integrated Coal and Gas Mining of Closely-Spaced Outburst Coal Seams: Results from a Case Study Including Mine Safety Improvements and Greenhouse Gas Reductions
}

\author{
Liang Cheng ${ }^{1,2} \oplus$, Zhaolong Ge ${ }^{2, *}$, Jiufu Chen ${ }^{3}$, Hao Ding ${ }^{1}$, Lishuang Zou ${ }^{3}$ and $\mathrm{Ke} \mathrm{Li}^{4, *}$ \\ 1 China Merchants Chongqing Communications Technology Research \& Design Institute Co., Ltd., \\ Chongqing 400067, China; chengliang@cqu.edu.cn (L.C.); dinghao@cmhk.com (H.D.) \\ 2 State Key Laboratory of Coal Mine Disaster Dynamics and and Control, Chongqing University, \\ Chongqing 400044, China \\ 3 Chongqing Energy Investment Group, Chongqing 400060, China; 20112002042@cqu.edu.cn (J.C.); \\ chengliang1@cmhk.com (L.Z.) \\ 4 National Engineering Laboratory for Highway Tunnel Construction Technology, Chongqing 40067, China \\ * Correspondence: gezhaolong@cqu.edu.cn (Z.G.); like1@cmhk.com (K.L.)
}

Received: 24 October 2018; Accepted: 31 October 2018; Published: 2 November 2018

check for updates

\begin{abstract}
Closely-spaced outburst coal seams (COCS) is the main condition of coal seams in southwest China, and gas disasters are one of the major problems affecting coal mine safety. Mining a protective seam and pre gas extraction are the most safety way to improve the efficiency of mining under these conditions. However, low pre-mining gas extraction efficiency coupled with the close proximity of adjacent working faces is a problem. When mining at an old working face has been completed but the new working face is not yet ready to be mined, coal-bed gasses can flow into the new working face from adjacent seams and this commonly causes methane monitoring instruments to sound an alarm. These gas extraction difficulties lead to a conflict between mine safety and profit. To solve these problems, a sequential approach for integrated coal and gas mining of closely-spaced outburst coal seams is introduced in this paper. Two fundamental principles are proposed: (1) Fully coordinating the spatiotemporal relationships between gas extraction, roadway development, and coal mining to maximize both mine safety and coal and gas production; (2) Defining a mining sequence for outburst coal seams and choosing the coal seam with the weakest outburst risk as the protective seam. A system for comprehensive gas extraction in underground coal mines is divided into four stages for gas extraction: gas extraction before coal roadway tunneling, gas extraction before coal mining, gas extraction during coal mining, and gas extraction from the goaf after coal mining. The Songzao mining area, China, is used as a case study to demonstrate the effectiveness of this model, and it brings three major benefits: it improves underground coal mine safety with physical gas accidents decreased by $66.8 \%$, it makes underground coal-bed methane (CBM) extraction more efficient with the average gas extraction rate were respectively $45.13 \mathrm{~m} 3 / \mathrm{t}$ and $62.4 \%$, the highest in China, and it reduces greenhouse gas emissions equivalent to 3.5 million tonnes of carbon dioxide. This study could be used as a valuable example for other coal deposits being mined under similar geological conditions.
\end{abstract}

Keywords: outburst coal seam; gas disaster; coal mining; gas extraction; greenhouse gas

\section{Introduction}

Coal is the main primary energy resource in China and accounts for more than $60 \%$ of the primary energy consumed in the country [1]. The southwest is one of 14 major coal production bases in China, 
however, is the main condition of coal seams in southwest China is closely-spaced outburst coal seams (COCS) with low permeability. This means the risk of coal and gas outburst disasters is more serious than in other mining areas [2,3]. During the period covered by China's Twelfth Five-Year Plan (2011-2015), gas accidents accounted for $64.4 \%$ of the total number of major accidents in coal mines in China and deaths due to gas accidents accounted for $69.7 \%$ of the total number of deaths due to major accidents, and gas accidents accounted for $58.8 \%$ of the country's accidents [4]. Clearly, gas control and gas disaster prevention are very important to China's coal industry.

Coal-bed methane (CBM) is a well-known as a hazard for mine safety and is a powerful greenhouse gas [5]. However, CBM is also a high quality and clean energy resource [6,7]. Wells drilled from the surface have developed CBM resources in the United States, Canada, Australia, and Poland [8]. Surface wells have also been used to control gas and prevent gas disasters in underground coal mines in China such as in the Jincheng mining area in the Qinshui Basin $[9,10]$. However, surface wells cannot play a role in southwest China for COCS with thin seams or with medium-thickness seam with low permeability is the main condition of coal seam [11]. For this reason, gas extraction from the workings in underground coal mines is the main method used to develop CBM and prevent gas disasters in China [12,13].

For outburst coal seams with low permeability, the sequential operations of tunneling and mining are disturbed by the low efficiency gas extraction. Mining a coal seam with low or with no outburst risk (called the protective seam) to increase the permeability of adjacent coal seams with a high outburst risk (called the protected seam) is a common practice in Chinese underground mines. This practice increases the efficiency of gas extraction and improves safety during subsequent coal mining [14,15]. However, where COCS are present, pressure on the adjacent seams will be reduced by mining the protective seam and the gas released by this reduction in pressure will flow into the seam being mined through fractures between the seams. This just can lead to a gas overrun (mine air $>1 \%$ methane) accident.

To integrate gas extraction and coal mining, the appropriate gas extraction techniques for different areas must be integrated and coordinated with the different stages of mining in both time and space. Activities such as the spatiotemporal relationship between gas roadway tunneling and gas pre-extraction, the temporal relationship between gas pre-extraction and the mining of protective seams, and the spatiotemporal relationships between the mining of protective and protected seams must all be considered.

Aiming at the problems described above, a sequential approach of integrated coal and gas mining of COCS is proposed. In this article, a case study of the Songzao mining area in China, the gas extraction techniques used in the mine are introduced and classified based on their application during the different stages of mining. The spatiotemporal relationships between gas extraction and coal mining are also described. Finally, the effects of coal mining and gas extraction in the Songzao mining area are analyzed in detail and unresolved problems are discussed. This case study sets a good example for other coal deposits being mined under similar geologic conditions.

\section{Regional and Mine Geology}

The Songzao mining area is located in Chongqing City, China. As the largest anthracite coal production center in southwestern China, the Songzao mining area supplies $70 \%$ of the coal for Chongqing. The coal measures in the mining area are in the Permian Longtan Formation. Coal is produced from three seams, identified, from top to bottom, as the $M_{6}, M_{7}$, and $M_{8}$ seams. The $M_{8}$ seam is the main production seam but coal is recoverable from the $\mathrm{M}_{6}$ and $\mathrm{M}_{7}$ seams at some localities. The spacing between the $M_{6}$ and $M_{7}$ seams ranges from 5 to $13 \mathrm{~m}$ and the spacing between the $M_{7}$ and $\mathrm{M}_{8}$ seams ranges from 4 to $12 \mathrm{~m}$, with an average of $10 \mathrm{~m}$.

Generally, a coal seam with a gas content of more than $8 \mathrm{~m}^{3} / \mathrm{t}$ or a gas pressure greater than $0.74 \mathrm{MPa}$ is considered to be an outburst risk seam [16]. Table 1 shows that the $\mathrm{M}_{6}, \mathrm{M}_{7}$, and $\mathrm{M}_{8}$ seams are all identified as outburst risk seams. All of the coal mines in the Songzao mining area are classified as coal and gas outbursts mines and the area is considered to host COCS with low permeability. 
Taken together, the high gas pressures, high gas contents, and low coal firmness coefficients make the seams very dangerous for outbursts. A total of 489 coal and gas outbursts have occurred in the Songzao mining area and an exceptionally large coal and gas outburst accident occurred in the Tonghua coal mine on 30 May 2009, causing the release of 7138 tonnes of bursting coal/rock and 285 thousand $\mathrm{m}^{3}$ of gas. The outburst resulted in 30 worker fatalities and 79 injuries.

Figure 1 shows a generalized stratigraphic column for the coal measures in the Songzao mining area [17]. The high gas contents of the coal seams in the Songzao mining area means that gas in the seams constitute a significant gas resource; the gas reserves in the Songzao mining area are around $38.3 \times 10^{9} \mathrm{~m}^{3}$. For COCS, gas is a potential resource but the coal should be mined only after the gas has been extracted.

Table 1. General characteristics of the $M_{6}, M_{7}$, and $M_{8}$ coal seams and gas in those seams in the Songzao mining area.

\begin{tabular}{|c|c|c|c|c|}
\hline Coal Seams & $\begin{array}{c}\text { Seam Thickness } \\
/ \mathrm{m}\end{array}$ & $\begin{array}{l}\text { Firmness } \\
\text { Coefficient }\end{array}$ & $\begin{array}{c}\text { Gas Content } \\
\qquad / \mathrm{m}^{3} / \mathrm{t}\end{array}$ & $\begin{array}{c}\text { Gas Pressure } \\
/ \mathrm{MPa}\end{array}$ \\
\hline \multirow{2}{*}{$\mathrm{M}_{6}$} & $0.75 \sim 1.3$ & \multirow{2}{*}{$0.3 \sim 1.2$} & $12.93 \sim 18.96$ & $1.4 \sim 3.7$ \\
\hline & 1.15 & & 14.58 & 1.8 \\
\hline \multirow{2}{*}{$\mathrm{M}_{7}$} & $1.07 \sim 2.8$ & \multirow{2}{*}{$0.3 \sim 1.0$} & $14.94 \sim 19.30$ & $1.5 \sim 4.8$ \\
\hline & 1.45 & & 16.89 & 2.1 \\
\hline \multirow{2}{*}{$\mathrm{M}_{8}$} & $2.10 \sim 4.97$ & \multirow{2}{*}{$0.1 \sim 0.8$} & $16.35 \sim 29.17$ & $1.5 \sim 6.5$ \\
\hline & 2.90 & & 19.70 & 2.8 \\
\hline
\end{tabular}

\begin{tabular}{|c|c|c|c|c|}
\hline No. & $\begin{array}{c}\text { Thickness } \\
(\mathrm{m})\end{array}$ & $\begin{array}{l}\text { Total } \\
(\mathrm{m})\end{array}$ & $\begin{array}{l}\text { Geological } \\
\text { column }\end{array}$ & $\begin{array}{l}\text { Petrographic } \\
\text { description }\end{array}$ \\
\hline 1 & 1.26 & 1.26 & & Fine sandstone \\
\hline 2 & 1.15 & 2.41 & & $\mathrm{M}_{6}$ coal seam \\
\hline 3 & 4.34 & 6.75 & & Mudstone \\
\hline 4 & 1.93 & 8.68 & $\equiv \equiv$ & Clay rock \\
\hline 5 & 1.62 & 10.30 & :.:.:: & Siltstone \\
\hline 6 & 3.89 & 14.19 & & Fine sandstone \\
\hline 7 & 0.29 & 14.48 & & Mudstone \\
\hline 8 & 1.45 & 15.93 & & $\mathrm{M}_{7}$ coal seam \\
\hline 9 & 5.80 & 21.73 & & Mudstone \\
\hline 10 & 0.50 & 22.23 & & Coal seam \\
\hline 11 & 2.97 & 25.20 & & Mudstone \\
\hline 12 & 2.90 & 28.10 & & $\mathrm{M}_{8}$ coal seam \\
\hline 13 & 2.00 & 30.10 & & Mudstone \\
\hline 14 & 0.40 & 30.50 & & $\mathrm{M}_{9}$ coal seam \\
\hline 15 & 2.20 & 32.70 & E=包 & Mudstone \\
\hline 16 & 2.20 & 34.90 & ل1.1 & Limestone \\
\hline
\end{tabular}

Figure 1. Generalized stratigraphic column for the coal measures in the Permian Longtan Formation in the Songzao mining area, Chongqing City, China. 


\section{Sequential Approach for Integrated COCS Coal and Gas Mining}

\subsection{Fundamental COCS Mining Principles}

There are many problems associated with coal mining and CBM development in the Songzao mining area. These include serious outbursts from coal seams, the low efficiency of gas pre-extraction, and the large quantity of gas emissions from adjacent seams. How to coordinate the sequential steps required for coal and gas mining is the key to integrated coal mining and gas extraction in COCS. The principles to ensure highly efficient, steady, and safe coal mining while maximizing gas exploitation are:

(1) Coordinate roadway tunneling, gas extraction, and coal mining. First, gas pre-extraction can be carried out in areas far from coal production. This can effectively reduce the gas content and pressure in order to prevent gas disasters during roadway tunneling and coal mining. Second, pressure relief gas extraction in mining areas can fully develop the gas to ensure safe coal mining. Finally, coal seam gas can be extracted from the goaf.

(2) Determine a reasonable mining sequence for outburst coal seams. It is necessary to mine protective seams in COCS sequences. Generally, the coal seam with the lowest outburst risk is mined first as a protective seam. In the Songzao mining area, the $\mathrm{M}_{7}$ seam is the protective seam and the $\mathrm{M}_{8}$ is the protected seam. Gas pressure in the protected seam will be relieved and the permeability of the protected seam will be enhanced substantially. Thus the gas in the protected seam will be extracted more completely. The high outburst risk in the protected seam will be reduced to a low outburst risk or no outburst risk. These steps will promote safe coal and gas mining.

\subsection{System for Gas Extraction in COCS Mines}

As shown in Figure 2, a comprehensive system for gas extraction has been established to improve the efficiency of gas extraction. Gas extraction can be divided into four main stages: pre-tunneling gas extraction, pre-mining gas extraction, gas extraction during coal mining (during-mining gas extraction), and gas extraction in goaf after coal mining (post-mining gas extraction). In these different stages of mining, different technologies should be used to extract gas from the mines. Gas extraction in these four stages is described in the following sections.

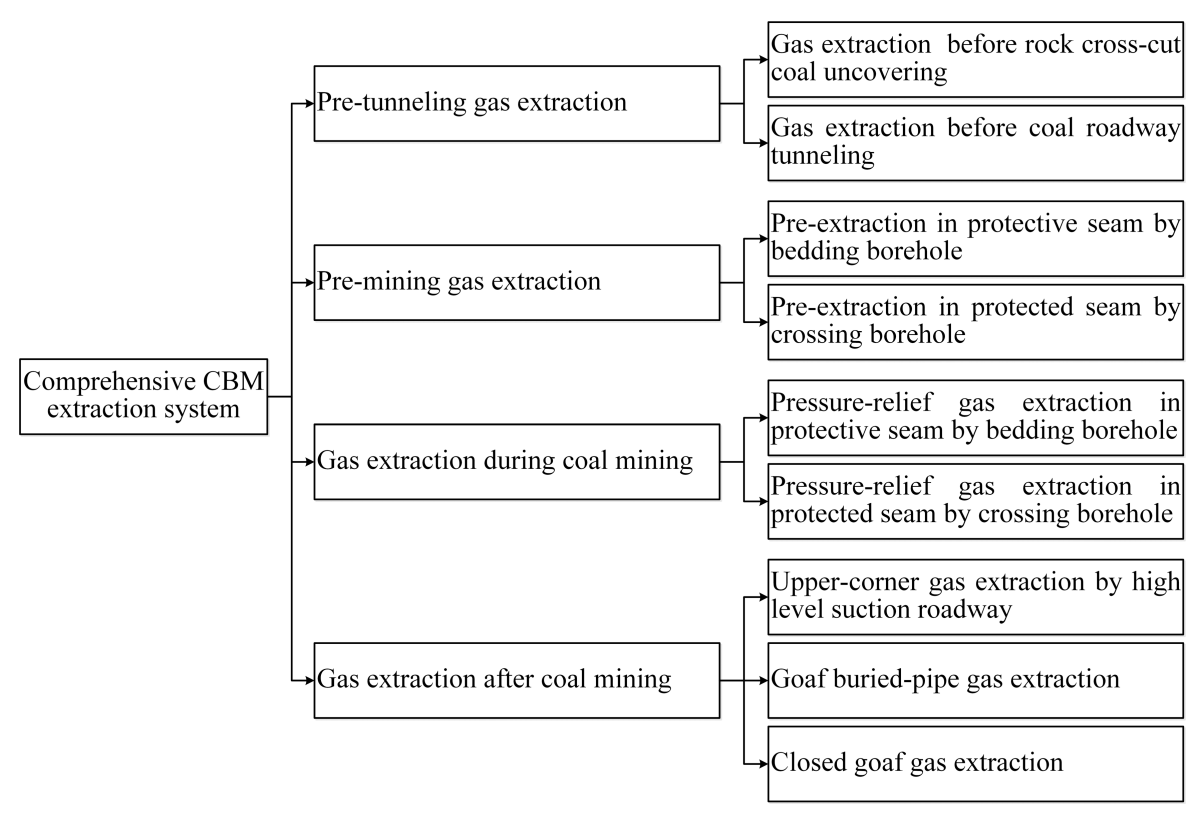

Figure 2. Diagram illustrating the comprehensive gas extraction system for the COCS mining model. 


\subsubsection{Pre-Tunneling Gas Extraction}

Pre-tunneling gas extraction is very important for rock cross-cut coal uncovering and coal roadway tunneling because gas disasters in outburst coal seams are most likely to happen during these operations. The purpose during this stage of extraction is mainly to reduce the gas pressure and the amount of gas in the coal seams. In order to prevent coal and gas outbursts, the gas content and pressure need to be decreased to a level less than the one at which coal and gas outbursts occur at the shallowest depths. This means that the gas pressure must be reduced to $0.74 \mathrm{MPa}$ or below and the gas content must be reduced to $8 \mathrm{~m}^{3} / \mathrm{t}$ or less $[16,18]$. In the Songzao mining area, only cross-measure boreholes can be used for pre-tunneling gas extraction.

However, the Songzao coal's low permeability means that this extraction technique is very inefficient and yields only small amounts of gas. Experience has shown that it is important to use hydraulic fracturing and water jet slotting to solve this problem. Hydraulic fracturing is used mainly in cross-measure boreholes to enhance seam permeability for gas extraction [19-21]. However, water jet slotting can be used to enhance seam permeability in both cross-measure boreholes and boreholes drilled parallel to bedding ("bedding boreholes") and water jet slotting also has another important function [22]. Because the fractures generated by hydraulic fracturing propagate mostly along the major principal stress direction, there will be zones in which the permeability is not enhanced. Water jet slotting can access these zones and partially make up for the lack of fractures generated by hydraulic fracturing.

(1) Gas pre-extraction for rock cross-cut coal uncovering

Cross-measure boreholes with small spans were used to extract the gas during rock cross-cut coal uncovering. As shown in Figure 3, the cross-measure boreholes were arranged $12 \mathrm{~m}$ lengths along the dip surface of the coal seam for rock cross-cut coal uncovering. The borehole spacing was commonly around $2-3 \mathrm{~m}$.

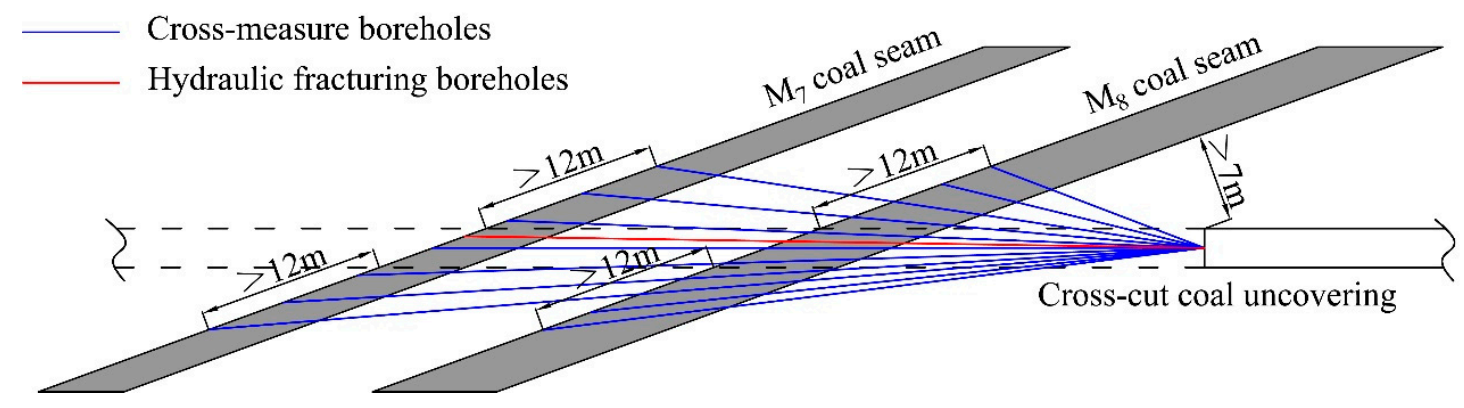

Figure 3. Layout for gas extraction boreholes for rock cross-cut coal uncovering.

In order to improve gas extraction, hydraulic fracturing was used to enhance seam permeability. The fracturing borehole was located in the center of the face of the roadway and drilled along the roadway alignment. The cross-measure borehole space could be increased to $4-8 \mathrm{~m}$ [23].

(2) Gas pre-extraction for coal roadway tunneling

For coal roadway tunneling, the cross-measure boreholes were arranged in a pattern extending $15 \mathrm{~m}$ on both sides of the roadways, as shown in Figure 4. The borehole space was designed to be approximately $6 \mathrm{~m}$ after seam permeability was enhanced by hydraulic fracturing. The fracturing boreholes were laid out along the roadway for a distance of 60-100 $\mathrm{m}$ [24]. 


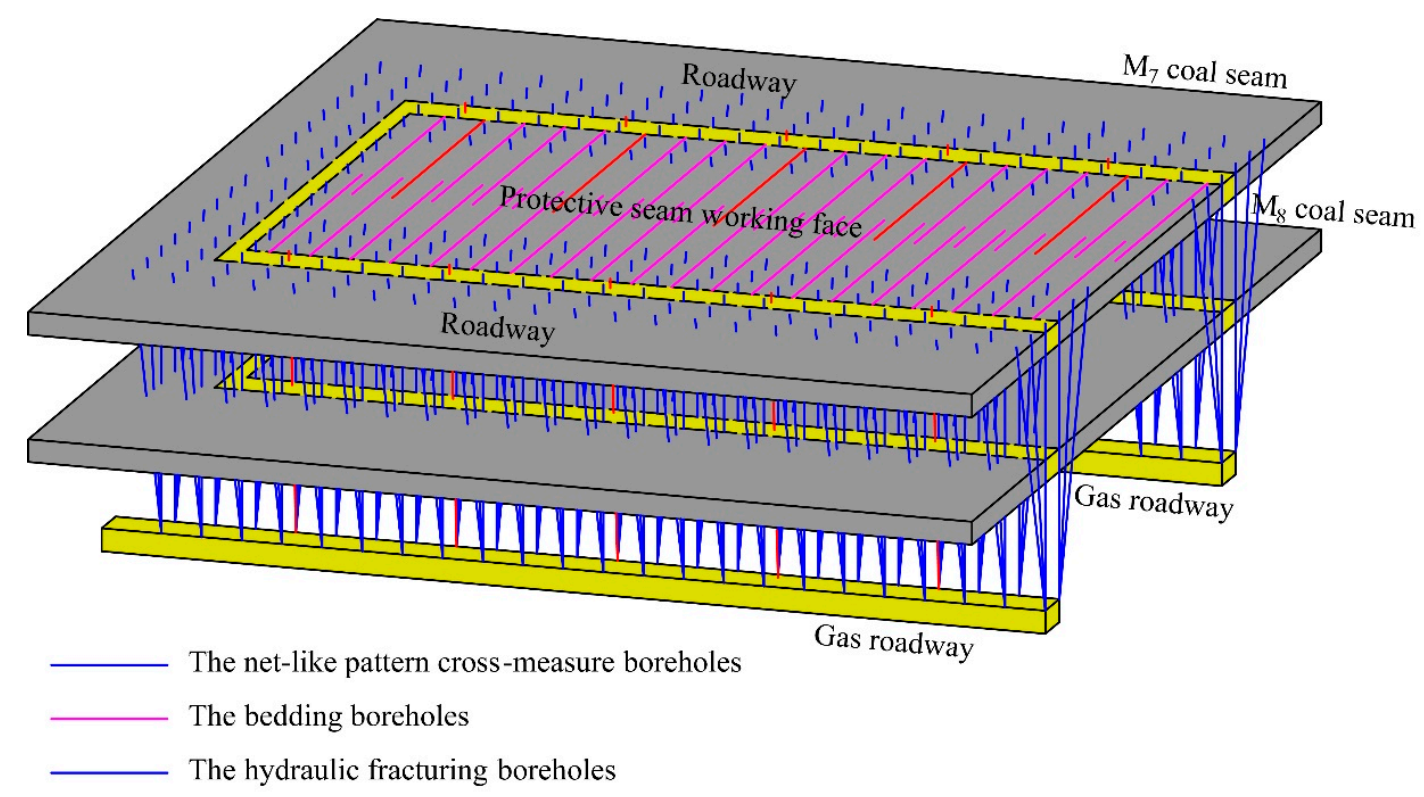

Figure 4. Layout for gas extraction borehole for protective seam.

\subsubsection{Pre-Mining Gas Extraction}

Pre-mining gas extraction can effectively reduce the gas content and pressure in the coal seams, eliminate outburst risks, and decrease gas emissions during mining. Pre-mining gas extraction can be divided into two classes; protective seam gas pre-extraction and protected seam gas pre-extraction. The main differences between the two classes are the differences in seam permeability and the extraction borehole layouts. The permeability of the protective seam is low and cross-measure boreholes and bedding boreholes should be drilled and used for gas extraction. In addition, permeability enhancement techniques, such as hydraulic fracturing and water jet slotting, should be used to enhance gas extraction. If these techniques are used, by the time mining of the protected seams commences, the permeability of the protected seam should already have been enhanced because the protected seam has undergone pressure relief after the mining of the protective seam. This means that the cross-measure boreholes in the protected seams should be sufficient for protected seam gas extraction.

(1) Pre-mining gas extraction in protective seams

There was a difference in spacing between protective seam and protected seam gas extraction boreholes. As shown in Figure 4, the borehole spacing was approximately 3-8 $\mathrm{m}$ for gas extraction from protective seams, whereas the borehole spacing for gas extraction from protected seams was 8-15 m (Figure 5).

In addition, bedding boreholes were used to extract gas from the mining area close to the workface to ensure safe mining. The borehole spacing there was approximately $5 \mathrm{~m}$, and some of the boreholes were fractured or water jet slotted to enhance seam permeability as shown in Figure 4 [25].

(2) Pre-mining gas extraction in protected seams

A net-like pattern of cross-measure boreholes with large spans was used to extract gas from the $\mathrm{M}_{8}$ coal seam (Figure 5) where it was below recoverable portions of the $\mathrm{M}_{7}$ coal seam. The cross-measure boreholes were drilled across the $\mathrm{M}_{8}$ coal seam after the bedding boreholes were drilled in the $\mathrm{M}_{7}$ coal seam and before the protective seam was mined. The borehole spacing was designed to be approximately $8 \mathrm{~m}$. The $\mathrm{M}_{7}$ coal seam, the protective seam, was mined first to enhance the permeability of $\mathrm{M}_{8}$ coal seam. This method has been proven to be the most effective method for seam permeability enhancement because it reduces gas content and pressure effectively. This promotes safety and efficiency at the working face. 


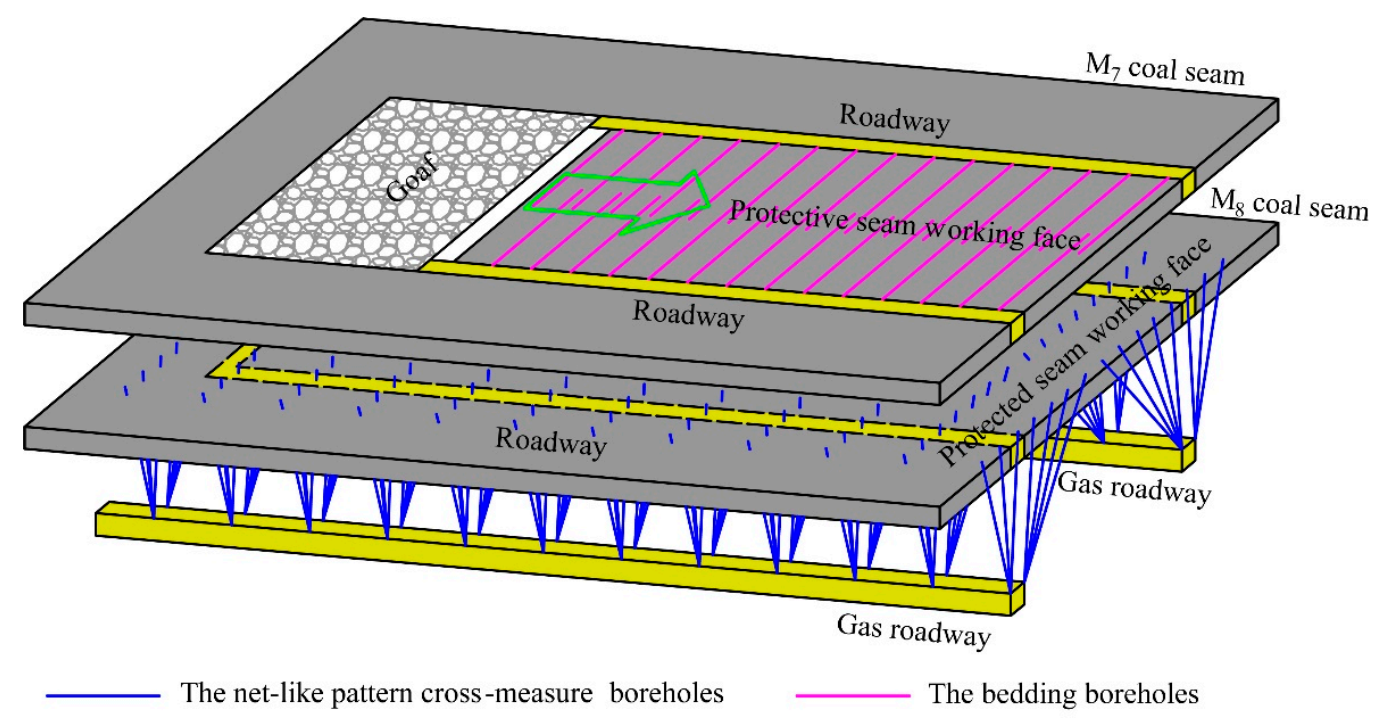

Figure 5. Layout for gas extraction boreholes before protected seam mining.

\subsubsection{Gas Extraction During Coal Mining}

Gas extraction during coal seam mining is mainly performed to prevent the upper-corner and air return roadway gas volume percentages from becoming too high and to ensure safe production. When mining COCS, methane gas overruns occur frequently and threaten mine safety. A "gas overrun" occurs when the return-air or the upper-corner gas volume exceeds $1 \%$ methane. Gas extraction during mining is intended to reduce the amount of CBM accumulating at the mining workface, control the return-air and the upper-corner methane concentrations, and improve the rate of gas extraction. Generally, the boreholes drilled for pre-mining gas extraction continue to be used for gas extraction during mining. A pressure relief zone is generated in the coal seam near the working face during coal mining and a large amount of adsorbed gas from the coal seam in the pressure relief zone will be desorbed [26]. The pre-extraction boreholes can be used to extract this gas effectively.

There is another gas extraction method, high-level roadway suction, which has been widely applied and this method played an important role in reducing the volume percentage of methane in upper-corner gas in the Songzao mining area.

The $\mathrm{M}_{7}$ coal seam is $1.45 \mathrm{~m}$ thick and the mining height is also $1.45 \mathrm{~m}$. According to Xiao et al. [27], the maximum height of the caving and fractured zones above the goaf can be calculated from Equations (1) and (2):

$$
\begin{aligned}
& h=\frac{100 M}{6.2 M+10}+2.5 \\
& H=\frac{100 M}{3.1 M+6}+6.5
\end{aligned}
$$

where $h$ is the height of caving zone, $H$ is the height of fractured zone, $M$ is the mining height.

Figure 6 shows a plan and profile of the roadway. At the same time, a row of high-level suction boreholes drilled from high-level suction roadway are used to extracted gas in pressure relief zone of $\mathrm{M}_{6}$ coal seam. 


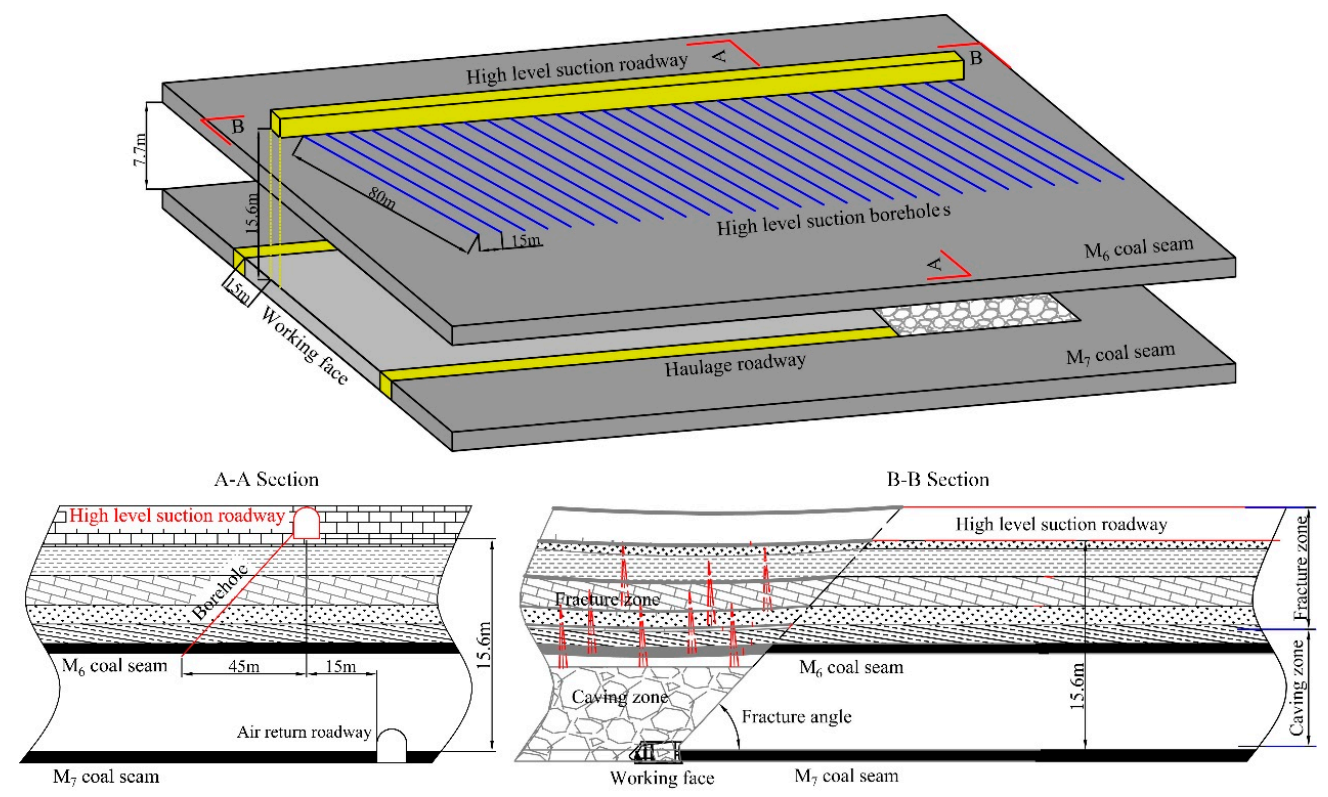

Figure 6. Diagrammatic sketches of the high-level suction roadway.

\subsubsection{Post-Mining Gas Extraction}

According to Coal Mine Safety Regulations, the goaf should be sealed after mining to prevent goaf air leakage. Leakage from the goaf can cause a gas explosion or spontaneous combustion, so gas extraction from the goaf plays an important role in controlling gas disaster [18]. In addition, as will be discussed later, methane from the goaf can be utilized for electric power generation. Buried pipes have been used widely for post-mining gas extraction in underground coal mines (Figure 7). Generally, low-negative pressure gas extraction can be used with a negative pressure of $3-4 \mathrm{kPa}$; this extraction method yields a gas with a low volume percentage of methane (3-5\%) [28]. Goaf gas extraction can decrease the methane concentrations and it can also reduce the amount of coal mine ventilation air required.

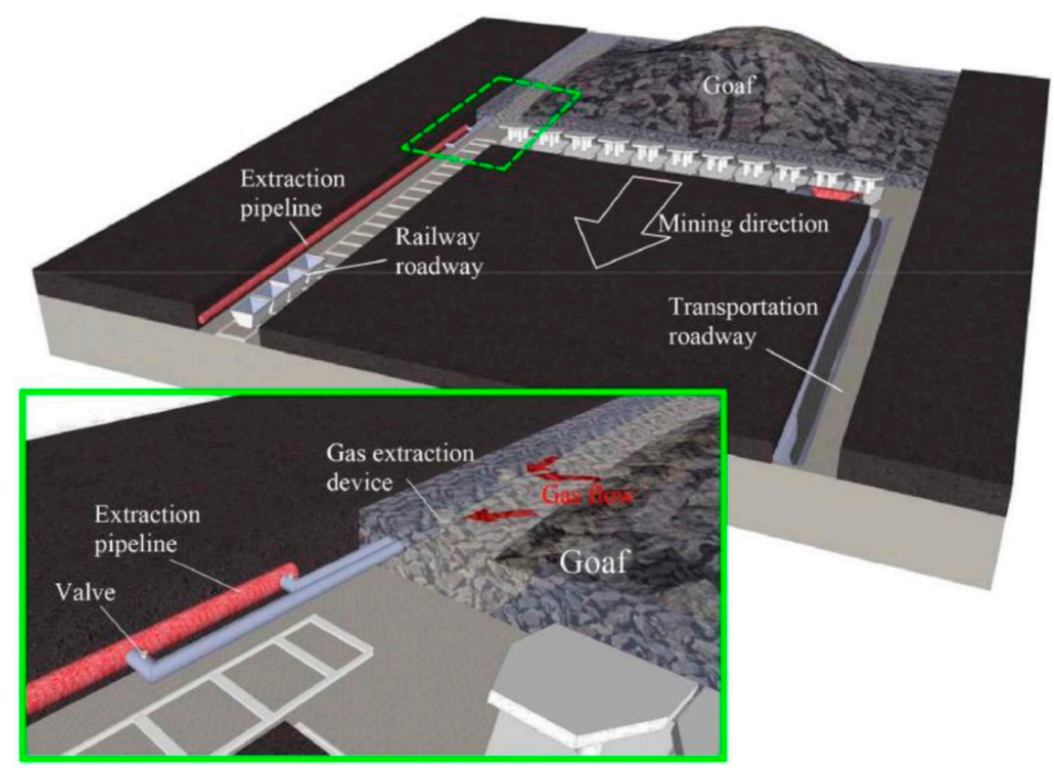

Figure 7. Sketch showing the pipe layout and geometry of the goaf buried-pipe gas extraction method. Reproduced with permission from [28]. 
Surface well gas extraction is another method that could conceivable be used but it has been shown that this method is not suitable for the Songzao mining area. There are two reasons the surface well gas extraction has not been used in this area:

(1) The Songzao mining area is located in the mountains in southwestern China and it is difficult and very expensive to drill the long holes from the surface necessary to reach the coal seams.

(2) The Songzao mining area coal seams are thin or of only medium-thickness and their permeabilities are low. Gas extraction efficiency using surface wells is very low.

\subsection{Details of the Integrated COCS Mining Approach}

A sequential approach for integrated coal and gas mining of COCS in underground coal mines has been proposed. The mining approach involves the judicious use of different gas extraction techniques and the temporal-spatial coordination of gas extraction, roadway tunneling, and coal mining. By using the mining approach, gas extraction and utilization has been maximized, gas disasters have been controlled, and coal has been mined safely and efficiently.

The sequential mining approach has three sections, respectively named the development section, the preparation section, and the mining section. In this mining approach, the roadways, mainly floor roadways, should be driven and gas extraction pipes should be installed in the development section. Installing this infrastructure first provides the time and space for pre-mining gas extraction. In the preparation section, pre-mining gas extraction has in most cases been completed to ensure that both coal roadway tunneling and coal mining can be done safely. Because of the coal's low permeability, hydraulic fracturing and water jet slotting, proven to enhance seam permeability, should be used for efficient gas extraction. In the mining section, protective seam mining should be done prior to protected seam mining so that the pressure relief provided by mining the protective seam can enhance the permeability of the protected seam.

To integrate the coal and gas mining, the timing of each mining activity has to be prescribed. The decisions to be made include when roadway tunneling prior to gas extraction should be initiated, how long pre-mining gas should be extracted prior to protective seam mining, and how much protective seam mining should be done prior to protected seam mining.

\subsubsection{Temporal Relationships of COCS Integrated Coal and Gas Mining}

Advance construction in a new mining level is required to provide time for gas pre-extraction and working face preparation before any coal mining is done in the new mining area.

(1) The development section

(a) Work for the development section should be begun 5 to 8 years prior to the preparation section. The timing for this section must consider the speed of rock roadway tunneling and the efficiency of gas extraction.

(b) A new gallery level should be deepened when the service life of the current mining level is less than 8 years.

(c) The recoverable period for developed coal reserves should be more than 5 years, the recoverable period for preparation coal reserves should be more than 1.5 years, and the recoverable period for workable reserves should be more than 1 year.

(d) The rock roadway, safety systems, and pipes in the new gallery level must be completed 1 to 1.5 years before the production capacity of the current mining level begins to decrease.

(e) All preparations for mining in the replacement mining area must be completed 6 months before the production capacity of the current mining area begins to decrease. 
(2) Gas extraction prior to coal mining

(a) Gas pre-extraction should be largely completed during the preparation section, and gas extraction should begin 3 to 5 years prior to coal mining. Determining the amount of lead time required must consider a number of factors including the coal seam's gas content and permeability, which techniques, if any, have been used to increase the coal seam's permeability, and the effectiveness of the extraction.

(b) Gas pre-extraction by cross-measure boreholes in thin and protective seams should initiated at least 12 months prior to coal roadway tunneling.

(c) In most cases, gas pre-extraction by bedding boreholes in protective seams should be done more than 3 months before coal mining begins.

(3) Protective seam advance mining

(a) The roadways for the protective seam working face should be finished 8 months before coal mining so that the requirements for gas extraction before mining of the first mined seam can be met.

(b) The first working face in a continuous mining area should be opened at least 6 months in advance of coal production.

(c) The replacement interval between adjacent working faces shall not be more than 3 months.

(d) The recoverable period for protected coal capacity for the coal mine should not be less than 24 months and the protected coal used for layout of the working face should not be less than 18 months.

\subsubsection{Spatial Relationship in COCS Integrated Coal and Gas Mining}

Advance construction provides the space for pre-mining gas extraction and for working face preparation in the new mining area.

(1) Advance tunneling distance

Figure 8 shows the spatial relationships of the roadways. The roadways that need to be tunneled in advance mainly involve development roadways, gas roadways, and coal roadways.

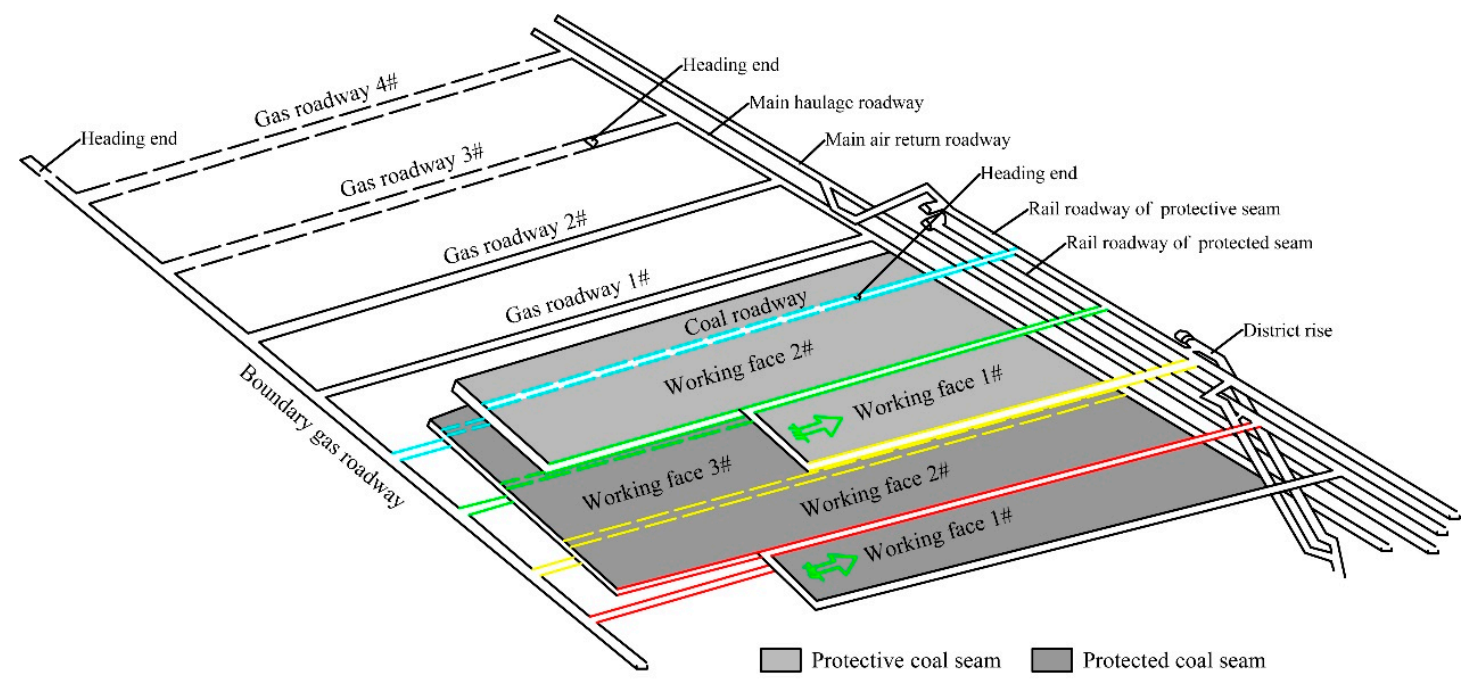

Figure 8. Sketch map showing the layout for and relationships between advance tunnels.

(a) A coal roadway must be prepared in advance of the working face in a protective seam to provide space for the next working face. The coal roadway tunneling begins as the working face of protective seam starts to be mined. 
(b) Gas roadways must be tunneled in advance of two working faces to provide space for gas pre-extraction by cross-measure boreholes. For example, tunneling for gas roadway \#3 will start when working face \#2 is being prepared while working face \#1 in the protective seam is being mined.

(c) The floor development roadway must be driven in advance of a working face or a gas roadway to provide space for construction of the next gas roadway. As shown in Figure 8, when the \#2 gas roadway has been finished, the heading end of the boundary gas roadway would have advanced beyond the \#3 gas roadway.

(2) Advance gas extraction distance

Advance gas extraction is done to provide a safe space for coal roadway tunneling and coal mining. Table 2 shows the distance in front of the working area from which the gas is extracted in the Songzao mining area.

Table 2. Minimum distance in advance of the specified project from which gas is extracted in the Songzao mining area.

\begin{tabular}{lc}
\hline \multicolumn{1}{c}{ Project } & $\begin{array}{c}\text { The Minimum Distance in Advance } \\
(\mathbf{m})\end{array}$ \\
\hline $\begin{array}{l}\text { Pre-tunneling gas extraction before coal roadway tunneling in } \\
\text { protective seam }\end{array}$ & 600 \\
$\begin{array}{l}\text { Pre-mining gas extraction before coal mining in protective seam } \\
\text { Pre-tunneling gas extraction before coal roadway tunneling in } \\
\text { protected outburst coal seam }\end{array}$ & 600 \\
$\begin{array}{l}\text { Pre-mining gas extraction before coal mining in protected seam } \\
\text { Net-like pattern of cross-measure boreholes for gas pre extraction } \\
\text { in protected seam when the protective seam start to mine }\end{array}$ & 1000 \\
\hline
\end{tabular}

(3) Protective seam advance mining distance

The size of the protected area is affected by the distance between the protective and the protected seams and the relief angle. The relief angle is commonly less than $90^{\circ}$ and the size of the protected area is reduced as the distance between the seams increases and the relief angle decreases. In order to ensure safe coal production, it is necessary to prepare a reasonable proportion of the working face in the protective layer and the working face in the protected layer. Generally, the ratio of the areas of the working surfaces of the protective and protected seams should be greater than 1.2:1.

\section{Effect of Integrated Coal and Gas Mining in the Songzao Mining Area}

\subsection{Coal and Gas Production}

The sequential approach of integrated COCS coal and gas mining has greatly improved both gas extraction efficiency and coal production. From 2010 to 2013, the amount of gas extracted and the coal produced in the Songzao mining area increased every year (Figure 9). Gas and coal production reached their maxima at 275 million cubic meters of gas and 5.81 million tonnes of coal in 2013. However production has declined since 2013 and there are two main reasons for this decrease:

(1) The Tonghua coal mine, one of the coal mines in the Songzao mining area, closed in 2016. Therefore, gas pre-extraction from this mine ceased in 2014 and the mine produced only coal until mine closure in 2016.

(2) After 2013, the economy in China began a transition and the demand for coal fell for a number of reasons. Consequently, coal production and sales fall sharply because they were affected by the country's economic downturn. 


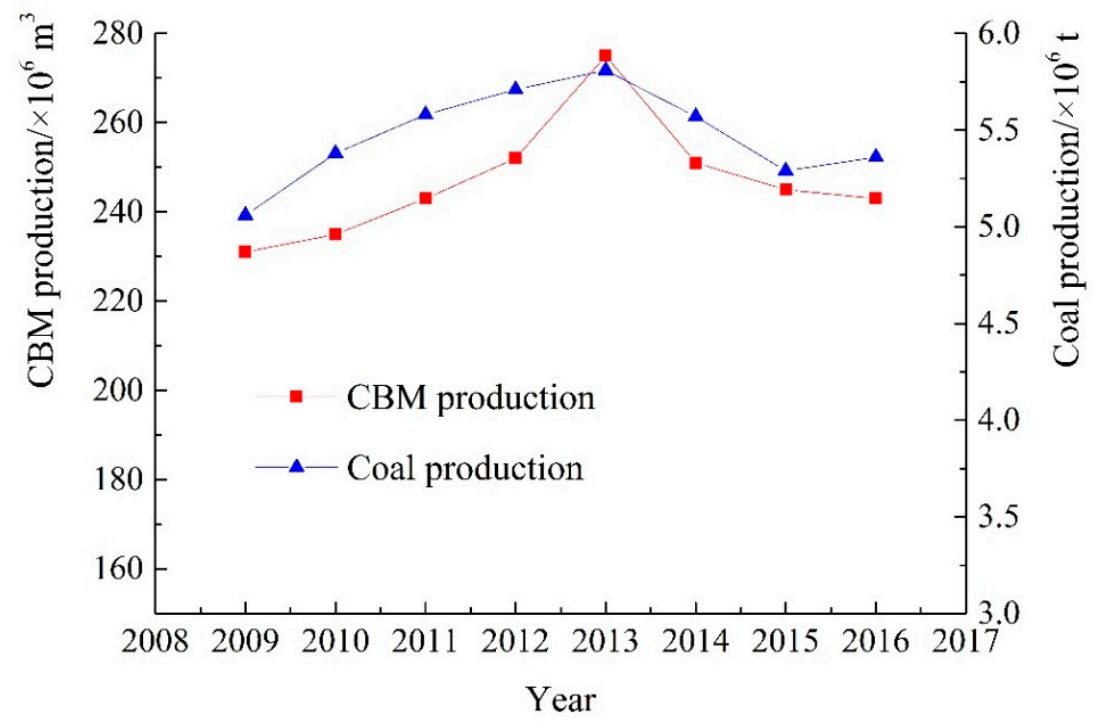

Figure 9. Coal and CBM production in the Songzao mining area for the years 2009-2016.

Figure 10 shows that the average gas extraction rate increased year by year, and the amount of gas extracted per tonne of coal mined remained fairly stable between 2009 and 2016. The average amount of gas extracted and the average gas extraction rate were respectively $45.13 \mathrm{~m}^{3} / \mathrm{t}$ and $62.4 \%$, the highest in China.

There may be two reasons for the increase of CBM extraction rate and CBM utilization rate: on the one hand, many new coal seam permeability enhancement technologies, such as water jet slotting [22,25], hydraulic fracturing [17,21,23,24] and oriented fracturing [19], have been applied since 2009. The efficiency of CBM extraction has been improved by application of these technologies, and it leads the amount of CBM extraction per unit time increasing. On the other hand, the time and space relationships between CBM extraction, roadway tunneling and coal mining have been planned in a reasonable way, and it provided sufficient pre-extraction time for CBM extraction.

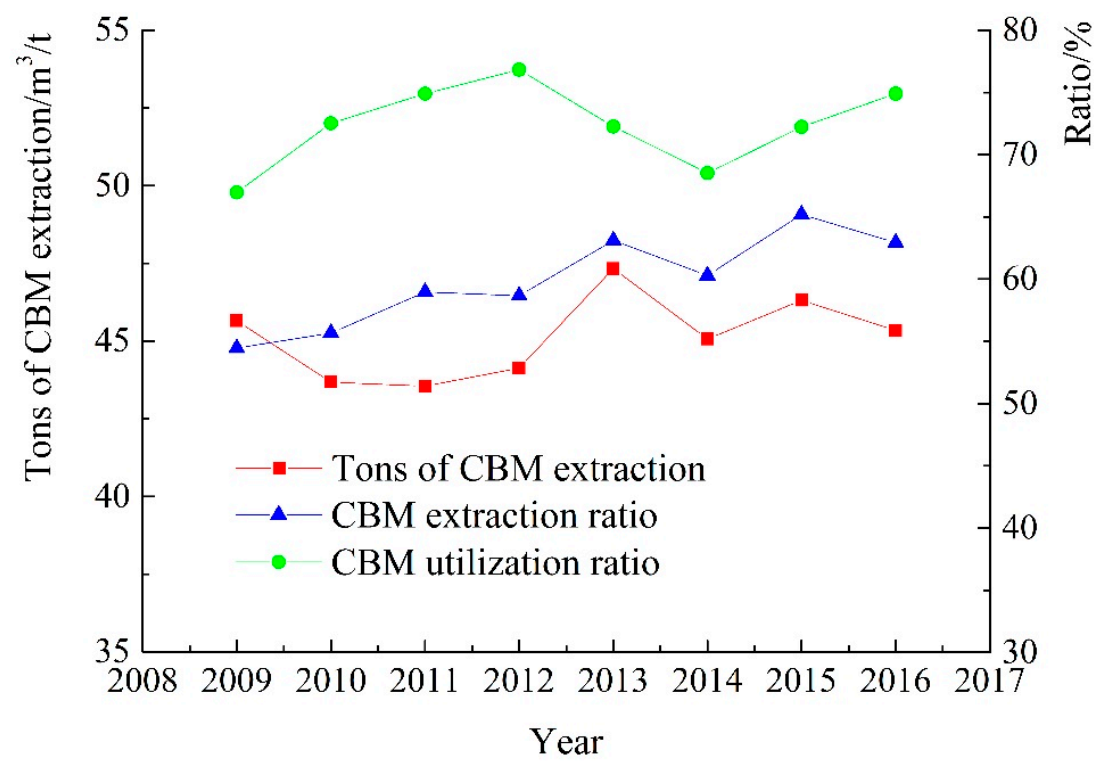

Figure 10. Coal-bed methane (CBM) production from the Songzao mining area. The extraction ratio and the percentage of CBM utilized are also shown. 


\subsection{Gas Utilization}

As a clean, efficient source of energy, CBM has been used widely in the Songzao mining area. To determine how the CBM is to be used, the gas produced has been divided into two classes. These classes are high-concentration gas (gas with more than $30 \%$ methane) and low concentration gas (everything else). Most of the high-concentration gas is used to meets the requirements for residents' daily life in Datong Town, Shihao Town, and Anwen Town, all located in the Songzao mining area. The remainder of the high-concentration gas is used for gas-fired electric power generation from three power stations with a total capacity of $30 \times 500 \mathrm{~kW}$. These electric power plants can generate about $70.3 \times 10^{6} \mathrm{kWh}$ of electricity while consuming almost 28.8 million cubic meters of CBM every year.

At present, the low concentration gas can only be used for electric power generation in China. Almost 11 million cubic meters of low methane concentration gas have been consumed by power plants with a total capacity of $12 \times 500 \mathrm{~kW}$; about $20 \times 10^{6} \mathrm{kWh}$ of electricity can be generated each year. The utilization ratio reaches $76.83 \%$ and this use of CBM for power generation reduces greenhouse gas emissions equivalent to 3.5 million tonnes of carbon dioxide per year. A flow chart for CBM utilization is shown in Figure 11.

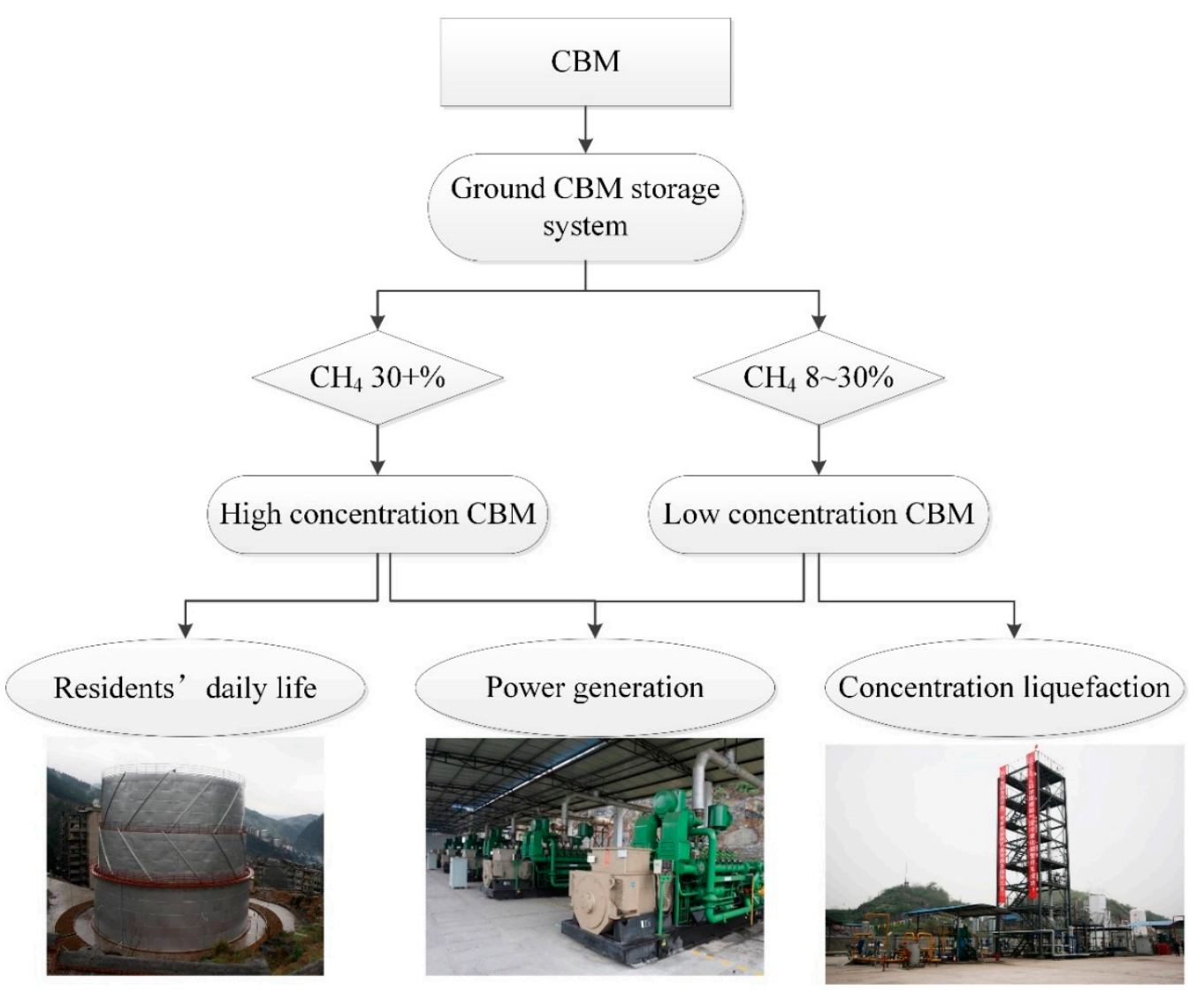

Figure 11. Flow chart for CBM utilization.

\subsection{Mine Safety}

Mine safety has been improved dramatically in the Songzao mining area and applying the sequential approach of integrated coal and gas mining in COCS makes the mines more efficient and economic. Between 2010 and 2016, gas monitoring limit incidents (overrun accidents) decreased by $76.3 \%$ and gas accidents/coal-gas outbursts decreased by $66.8 \%$. Most importantly, deaths due to gas accidents decreased by $45.1 \%$. No coal-gas outburst occurred during gas extraction operations and there were no coal-gas outburst deaths in 2013 or 2014. Having realized safe and efficient mining, the amount of safely produced coal reached a maximum of 5.81 million tonnes in 2013. The improvement of mine 
safety in the Songzao mining area benefits from efficient gas extraction and reasonable time-space relationships between CBM extraction, roadway tunneling and coal mining. The risk of gas disaster has been reduced by high efficiency CBM extraction. And the reasonable time-space relationships provide sufficient time and space to prevent gas disasters.

\subsection{Unresolved Problems}

Although the amount of CBM extracted is increasing each year, there are still several problems that need to be resolved:

(1) Bedding boreholes in soft coal seams are difficult to drill and tend to collapse easily. The effectiveness of gas extraction in these holes is poor and the extraction times are long. This leads to only partial gas extraction and gas disasters commonly occurred in these areas during coal mining and roadway tunneling. As a result, cross-measure boreholes must be used as a pre-extraction method to extract the CBM. This makes the gas extraction program more time consuming and expensive.

(2) Because the low permeability of coal seams in the Songzao mining area limits gas extraction, the number of boreholes per unit area must be high; a very large number of holes must be drilled. The result is long construction periods and high costs [29]. To increase the extraction efficiency of the holes, hydraulic fracturing and water jet slotting must be used to enhance seam permeability and achieve satisfactory CBM extraction.

(3) Poor sealing of gas extraction boreholes leads to dilution of the CBM extracted resulting in a low volume percent of methane in the gas delivered for utilization. Gas extracted from the Songzao area mines, for example, contains less than $30 \%$ volume percent methane and this accounts for approximately $75 \%$ of the total amount of gas extracted. If the CBM extracted is to be used more efficiently, the volume of methane in the extracted gas must be increased.

\section{Conclusions}

(1) In order to solve the problems that gas extraction difficulties lead to a conflict between mine safety and profit, a sequential approach for integrated coal and gas mining of closely-spaced outburst coal seams has been designed. The fundamental principles for integrated coal and gas mining in COCS is formulates and a system for comprehensive gas extraction in underground coal mines is established. The COCS mining approach can be used in other coal deposits being mined under similar geologic conditions. The COCS mining approach fully coordinates the spatiotemporal relationships between gas extraction, roadway development, and coal mining to ensure mine safety and maximize coal and gas mining efficiency. The mining approach specifies the sequences for coal mining and gas extraction operations in outburst coal seams and stipulates that the coal seam with the weakest outburst risk be used as the protective seam. Gas extraction in COCS is divided into four stages: extraction before coal roadway tunneling, extraction before coal mining begins, extraction during coal mining, and gas extraction from the goaf after coal mining. Gas extraction using cross-measure boreholes, bedding boreholes, a high-level suction roadway, and buried pipes are used for these different stages.

(2) The spatiotemporal relationships between gas extraction, roadway development, and coal mining during the different stages needed to develop a coal mine panel are discussed in three sections in the COCS mining approach. The development section proposes that the floor roadways should be tunneled in advance to provide time and space for pre-mining gas extraction. In the preparation section, the mining approach explains that pre-mining gas extraction should be completed to ensure that both coal roadway tunneling and coal mining can be done safely. In the mining section, the mining approach proposed that protective seam mining should be done months prior to protected seam mining so that protective seam mining can enhance the permeability of the protected seam and thus improve gas extraction efficiency. 
(3) The Songzao mining area is taken as a typical case to demonstrate the effectiveness of this mining approach. The mining approach brought three major benefits:

Improved mine safety. Between 2010 and 2016, coal production reached a maximum at 5.81 million tons in 2013 but gas exceeding gas monitoring instrument detection limit accidents decreased by $76.3 \%$, physical gas accidents decreased by $66.8 \%$, and the deaths due to gas accidents decreased by $45.1 \%$.

Improved coal-bed methane extraction. The amount of gas extracted reached a maximum at 275 million cubic meters. The average tons of gas extraction and the average gas extraction rate were respectively $45.13 \mathrm{~m}^{3} / \mathrm{t}$ and $62.4 \%$, the highest in China.

Application of the COCS sequential mining approach also reduced greenhouse gas emissions. The utilization ratio in the mine used for this case study reached $76.83 \%$ and this reduces greenhouse emissions equivalent to 3.5 million tons of carbon dioxide.

Author Contributions: Funding Acquisition, Z.G., H.D., K.L.; Investigation, L.C, L.Z.; Methodology, J.C.; Resources, J.C.; Writing-Original Draft Preparation, L.C.; Writing-Review \& Editing, Z.G.

Funding: This study was financially supported by the National Science and Technology Major Projects of China (Grant No. 2016ZX05045), the National Natural Science Foundation of China (NSFC) (Grant No. 51804055, No. 51504046 and No. 41601574).

Acknowledgments: We thank David Frishman, from Liwen Bianji, Edanz Group China (www.liwenbianji.cn/ac), for editing the English text of a draft of this manuscript.

Conflicts of Interest: The authors declare no conflict of interest.

\section{References}

1. Jiang, B.; Sun, Z.Q.; Liu, M.Q.; Jin, H.G.; Zhang, X.L. China's energy development strategy under the low-carbon economy. Energy 2010, 35, 4257-4264. [CrossRef]

2. Beamish, B.B.; Crosdale, J.P. Instantaneous outbursts in underground coal mines: an overview and association with coal type. Int. J. Coal Geol. 1998, 35, 27-55. [CrossRef]

3. Fisne, A.; Esen, O. Coal and gas outburst hazard in Zonguldak Coal Basin of Turkey, and association with geological parameters. Nat. Hazards 2014, 74, 1363-1390. [CrossRef]

4. Wang, L.; Cheng, Y.P.; Liu, H.Y. An analysis of fatal gas accidents in Chinese coal mines. Saf. Sci. 2014, 62, 107-113. [CrossRef]

5. Cheng, Y.P.; Wang, L.; Zhao, X.L. Environmental impact of coal mine methane emissions and responding strategies in China. Int. J. Greenh. Gas. Control 2011, 5, 157-166. [CrossRef]

6. Flores, R.M. Coalbed methane: From hazard to resource. Int. J. Coal Geol. 1998, 35, 3-26. [CrossRef]

7. Karacan, C.Ö.; Felicia, A.R.; Michael, C. Coal mine methane: A review of capture and utilization practices with benefits to mining safety and to greenhouse gas reduction. Int. J. Coal Geol. 2011, 86, 121-156. [CrossRef]

8. Psaltis, S.; Farrell, T.; Burrage, K.; Burrage, P.; Mccabe, P.; Moroney, T. Mathematical modelling of gas production and compositional shift of a csg (coal seam gas) field: local model development. Energy 2015, 88, 621-635. [CrossRef]

9. Liu, H.; Sang, S.; Formolo, M.; Li, M.; Liu, S.; Xu, H. Production characteristics and drainage optimization of coalbed methane wells a case study from low permeability anthracite hosted reservoirs in southern Qinshui Basin China. Energy Sust. Dev. 2013, 17, 412-423. [CrossRef]

10. Kong, S.L.; Cheng, Y.P.; Ren, T.; Liu, H.Y. A sequential approach to control gas for the extraction of multi-gassy coal seams from traditional gas well drainage to mining-induced stress relief. Appl. Energy 2014, 131, 67-78. [CrossRef]

11. Zhou, H.X.; Yang, Q.L.; Cheng, Y.P.; Ge, C.G.; Chen, J.X. Methane drainage and utilization in coal mines with strong coal and gas outburst dangers: A case study in Luling mine, China. J. Nat. Gas Sci. Eng. 2014, 20, 357-365. [CrossRef]

12. Yuan, L.; Lin, B.Q.; Yang, W. Research progress and development direction of gas control with mine hydraulic technology in China coal mine. Coal Sci. Technol. 2015, 43, 45-49.

13. Zhou, F.B.; Xia, T.Q.; Wang, X.X.; Zhang, Y.F.; Sun, Y.N.; Liu, J.S. Recent developments in coal mine methane extraction and utilization in China: A review. J. Nat. Gas Sci. Eng. 2016, 31, 437-458. [CrossRef] 
14. Sun, Q.; Zhang, J.X.; Zhang, Q.; Yin, W.; Germain, D. A protective seam with nearly whole rock mining technology for controlling coal and gas outburst hazards: A case study. Nat. Hazards 2016, 84, 1793-1806. [CrossRef]

15. Liu, Y.K.; Zhou, F.B.; Liu, L.; Liu, C.; Hu, S.Y. An experimental and numerical investigation on the deformation of overlying coal seams above double-seam extraction for controlling coalmine methane emissions. Int. J. Coal Geol. 2011, 87, 139-149.

16. State Administration of Work Safety. Coal Mine Safety Regulations; China Coal Industry Publishing House: Beijing, China, 2016; pp. 56-119. ISBN 978-7-5020-3589-1.

17. Cheng, L.; Ge, Z.L.; Xia, B.W.; Li, Q.; Tang, J.R.; Cheng, Y.G.; Zuo, S.J. Research on Hydraulic Technology for Seam Permeability Enhancement in Underground Coal Mines in China. Energies 2018, 11, 427. [CrossRef]

18. State Administration of Work Safety. Provisions of the Prevention of Coal and Gas Outburst; China Coal Industry Publishing House: Beijing, China, 2017; pp. 83-136. ISBN 978-7-5020-5227-0.

19. Liu, Y.; Xia, B.; Liu, X. A novel method of orienting hydraulic fractures in coal mines and its mechanism of intensified conduction. J. Nat. Gas Sci. Eng. 2015, 27, 190-199. [CrossRef]

20. Zhang, J.C.; Bian, X.B. Numerical simulation of hydraulic fracturing coalbed methane reservoir with independent fracture grid. Fuel 2015, 143, 543-546. [CrossRef]

21. Lu, Y.Y.; Yang, F.; Ge, Z.L.; Wang, Q.; Wang, S.Q. Influence of viscoelastic surfactant fracturing fluid on permeability of coal seams. Fuel 2017, 194, 1-6. [CrossRef]

22. Lu, Y.Y.; Liu, Y.; Li, X.H.; Xia, B.W. A new method of drilling long boreholes in low permeability coal by improving its permeability. Int. J. Coal Geol. 2010, 84, 94-102. [CrossRef]

23. Sun, D.F.; Chen, J.F.; Long, J.M.; Li, W.S.; Mei, X.D. Experimental study on high pressure hydraulic fracturing technology to uncover coal in cross-cut. Coal Sci. Technol. 2013, 41, 163-165.

24. Dong, G.F.; Zhai, J.; Zou, L.S.; Yin, X.L. Application of Hydraulic fracturing technology on increasing coal tunneling. J. North China Inst. Sci. Technol. 2013, 10, 22-28.

25. Ge, Z.L.; Mei, X.D.; Jia, Y.J.; Lu, Y.Y.; Xia, B.W. Influence radius of slotted borehole drainage by high pressure water jet. J. Min. Saf. Eng. 2014, 31, 657-664.

26. Hu, G.Z.; Wang, H.T.; Li, X.H.; Fan, X.G.; Yuan, Z.G. Numerical simulation of protection range in exploiting the upper protective layer with a bow pseudo incline technique. Min. Sci. Technol. 2009, 19, 58-64. [CrossRef]

27. Xiao, J.F.; Fan, S.X.; Lu, P.; Chen, Y.Y.; Chen, F. Layout parameter optimization of highly-located drainage roadway along seam for controlling gas with pressure relief from close-distance methane-rich seam group. J. Min. Saf. Eng. 2016, 33, 564-570.

28. Wang, H.F.; Cheng, Y.P.; Wang, W.; Xu, R. Research on comprehensive CBM extraction technology and its applications in China's coal mines. J. Nat. Gas Sci. Eng. 2014, 20, 200-207. [CrossRef]

29. Wu, Y.; Liu, J.S.; Elsworth, D.; Miao, X.X.; Mao, X.B. Development of anisotropic permeability during coalbed methane production. J. Nat. Gas Sci. Eng. 2010, 2, 197-210. [CrossRef] 